Review

\title{
Devices and Protocols for Upper Limb Robot-Assisted Rehabilitation of Children with Neuromotor Disorders
}

\author{
Valeria Falzarano ${ }^{1,2, * \mathbb{D}}$, Francesca Marini ${ }^{1}$, Pietro Morasso ${ }^{1}$ and Jacopo Zenzeri ${ }^{1}$ (D) \\ 1 Robotics, Brain and Cognitive Sciences Department, Istituto Italiano di Tecnologia, Via Enrico Melen 83, \\ 16152 Genova, Italy \\ 2 Department of Informatics, Bioengineering, Robotics and System Engineering, University of Genova, \\ Viale Causa 13, 16145 Genova, Italy \\ * Correspondence: valeria.falzarano@iit.it
}

Received: 31 May 2019; Accepted: 27 June 2019; Published: 1 July 2019

\begin{abstract}
Neuromotor disorders negatively affect the sensorimotor system, limiting the ability to perform daily activities autonomously. Rehabilitation of upper limb impairments is therefore essential to improve independence and quality of life. In the last two decades, there has been a growing interest in robot-assisted rehabilitation as a beneficial way to promote children recovery process. However, a common understanding of the best drivers of an effective intervention has not been reached yet. With this aim, the current study reviewed the existing literature on robot-assisted rehabilitation protocols for upper extremities in children, with the goal of examining the effects of robotic therapy on their sensorimotor recovery process. A literature search was conducted in several electronic database to identify the studies related to the application of robotic therapy on upper limbs in the pediatric population. We analyzed three reviews and 35 studies that used 14 different robotic devices, and an overview of their characteristics, applications in the clinical setting and results is provided. Besides, the potential benefits of robot-assisted assessment and therapy are discussed to identify the key factors yielding positive outcomes in children. Finally, this review aim to lay the foundations for more effective neuroplasticity-enhancement protocols and elicit insights into robot-based approaches.
\end{abstract}

Keywords: robot-assisted rehabilitation; upper limb; pediatric population; neurological disorders

\section{Introduction}

Robot-assisted rehabilitation consists in the use of mechatronic devices that can execute one or more tasks autonomously and can be used to apply rehabilitation protocols with the goal of promoting children's sensorimotor recovery [1]. In this work, we reviewed how robotic rehabilitation has been applied to some specific neurological motor disorders, Cerebral Palsy, Stroke and Acquired Brain Injury, chosen according to their impact, epidemiology and their suitability to exploit the technological advantages. Cerebral Palsy $(\mathrm{CP})$ is a group of permanent movement disorders that appears in early childhood and affects 200 children over 100,000 live births [2]. It is due to non-progressive disorders (such as asphyxia, genetic factors, malformations, cerebrovascular events and placental pathology) that affect the developing fetal or infant brain (up to 3 years of age) causing permanent disturbances in the development of the movement and posture [3,4]. Perinatal stroke, which occurs between the 20th week of gestation and the 28th postnatal day [5], is the most common cause of cerebral palsy with over $2 / 3$ of children that had experienced a perinatal stroke also having cerebral palsy. Stroke affects a range of 1.3 to 13 cases over 100,000 children [6]; it can be ischemic stroke, when a blood vessel is blocked, or hemorrhagic stroke, when a bleed occurs in the brain [7]. Acquired Brain Injuries (ABI) occur after birth and are not related to congenital factors; among the possible types of ABIs, 
Traumatic Brain Injury (TBI) is the most common one, and it is caused by sudden, traumatic physical damages of the brain [8]. It presents an impressive annual incidence among children, with 691 cases over 100,000 [9]. The general feature of these neurological disorders consists in resulting damages to the sensorimotor system, sometimes also accompanied by impaired cognitive abilities. In particular, children with $\mathrm{CP}$ present a decreased performance in motor control, muscle weakness, spasticity and they might be affected by partial or restricted muscle weakness (hemiparesis) or paralysis (hemiplegia) on the contralateral side of the body with respect to the brain hemisphere in which the damage has occured [10]. Also functional impairments are observed in children with stroke, who usually present deficits in coordination, dexterity, strength and movement speed on both side of the body, including the unaffected part [11]. Given the negative impact that these sensorimotor deficits have on the child's ability to perform activities of daily living (ADLs), treatment of upper limb impairments is crucial to improve their independence and quality of life. Accordingly, in this work we chose to focus on upper limbs robotic rehabilitation, with no consideration of robotic devices and protocols for lower limbs, although this is an equally relevant aspect of robot rehabilitation that would need a proper independent analysis.

Robot-assisted rehabilitation of upper limbs can be performed by means of two distinct classes of devices: end-effector robots, connected to a specific part of the body, and exoskeletons that can be considered as a motorized version of orthotic devices. While exoskeletons are "worn" by the users and their activation affects at the same time several joints, in the end-effector devices the user usually grasps the robot handle [12].

Surprisingly, although a wide spectrum of upper limb rehabilitation devices has been developed so far, at least in a preliminary proof-of-concept phase, in the great majority of cases they were specifically intended for adult users, with low possibility to adapt to children's biomechanics, as they do not provide the possibility to make changes in size, weight and forces delivered.

Despite this limited number of devices developed for the pediatric population, several studies have shown that their use can offer important opportunities in promoting child's sensorimotor recovery and/or in preventing the progression of the disease [13-15].

In addition to the previous considerations, we should take into account that neuroscience and advanced robotics have made available to the rehabilitation area the chance of a massive training and cognitive engagement, which have been demonstrate to be crucial factors for a successful rehabilitation. More precisely, the combination of robotic tasks with virtual reality environments provides an enriched experience that causes a higher focus and attention, novelty, fun and challenge, that all together maximize the cognitive engagement, thus stimulating child's active voluntary participation and, most importantly, neuroplasticity [16]. Indeed, it has been shown that active participation is more beneficial in promoting the sensorimotor recovery in comparison to the passive training, because when passive motion is predominant, the motor system tends to behave as a "greedy" optimiser decreasing the voluntary control of movement and the muscle activation $[17,18]$. Besides, it is worth highlighting that neuroplasticity is the most significant factor to consider when trying to design a personalized neurorehabilitation process. Neuroplasticity is the brain's ability to reorganize itself by forming new neural connections as a result of learning in response to new situations or to changes in their environment as well as a mechanism to compensate for brain injury [19]. Up to date, there are interesting findings that show how robotic rehabilitation, besides improving motor performance, is able to promote neuroplasticity and modulate functional connectivity of sensorimotor networks [20]. However, despite those studies have been mainly conducted on the adult population, it is reasonable to assume that children would achieve results not only similar, but even more promising [21]. Indeed, previous studies showed evidence of remarkable ability of children's brain to continue to myelinate and produce new dendritic connections after a trauma, further more than how much it happens in the adult population [22,23]. Particularly, in children, who suffer from brain lesions acquired during the first stages of life, the neural connections are immature and therefore it predominates the need to habilitate their brain during maturation, such as to teach them motor skills by strengthening 
alternative neuromotor networks [24]. Moreover, children with congenital disorders are not aware of what function they could and should aim at recovering, because they have not fully aware of the benefits of full arm function and of the effects of their impairments. As a consequence, in most of the cases, they do not take rehabilitative program seriously while instead high levels of commitment and motivation need to be promoted to reach success in the rehabilitation process. Importantly, several studies reported that these levels of engagement were elicited and maximized in children by the use of robotic devices, just simply because participants appreciated the game-like environment $[25,26]$.

Among the greatest potential of robotic rehabilitation lies the possibility to program the robotic device according to different types of control strategies chosen depending on the type and severity of the patient's impairment and on the phase of the rehabilitation treatment. These strategies are called active, passive, assistive and resistive and each of them may be more suitable for each specific clinical case.

In more details, in the active strategy, the robot provides no haptic feedback and requires subject's active motion; in the passive mode, the robot simulates therapist's work and passively moves child's arms to help them to accomplish the movement; differently, in the resistive mode, the robot interferes with the child movements opposing forces $[27,28]$; finally, in the assistive mode, the robot evaluates child's performance and adjusts the level of assistance accordingly. Assistive strategies can be: impedance-based assistance that usually exploit the position information of the patient's arm in order to provide assistance and are typically called assist-as-needed; triggered that allows the subject to initiate the movement and the assist-as-needed approach starts only after a specific performance parameter has reached a threshold; weight counterbalancing which supports the arm and the robot weight; performance-based that evaluates online pre-determined performance indicators and adjusts the training parameters of interest accordingly [29].

All these factors analyzed above lead to the conclusion that the use of robot-assisted rehabilitation could induce increasing potential benefits to the child's recovery process, thus improving the damaged or loss sensorimotor functions. When these robots are used in clinical rehabilitation, the presence of a therapist plays a crucial role, not only to offer support during the training, but mainly because a key factor is the constant monitoring of child's posture, motivation and effort, the control of their tiredness and their level of attention.

Presently, we can assume that the reason behind the increasing interest in rehabilitation robotics for the pediatric population is mainly due to the evidence provided by several studies which have showed how a greater functional improvement is acquired in robot-assisted rehabilitation compared to the conventional clinical treatments $[13,14,30,31]$. Moreover, another key point in the use of robotic devices in the clinical setting is that, besides training, they have been used to evaluate the children's motor functions by integrating traditional clinical assessments with more objective, reliable and accurate measurements [32]. Indeed, the devices can collect the kinematic, kinetic and dynamic data, related to the upper limbs, during the robotic intervention itself, in order to characterize and classify subject's impairment and/or to define the effectiveness of robotic training [33].

Although there are examples of robots used for the functional assessment (see subsection on robotic assessment), in most of the studies examined, the evaluation of rehabilitation treatment is based on clinical scales. Among these, the most common are the following ones: the Quality of Upper Extremity Skills Test (QUEST) to evaluate movement patterns and hand function [34], the Modified Ashworth Scale (MAS) to measure the upper limb degree of spasticity based on the muscle resistance to passive stretches [35], the Fugl-Meyer Assessment (FMA) to quantitatively measure the sensorimotor impairments [36], the Melbourne Assessment of Unilateral Upper Limb Function (MAUULF) to assess the quality of the movements [37], the Besta Scale to evaluate both capacity and performance of children's hand [38], the Assisting Hand Assessment (AHA) or the Assisting Hand Assessment for children from 18 months to 12 year (Kids-AHA) to measure the ability of their affected hand while performing bimanual activities [39] and, finally, the Box and Block Test (BBT) to evaluate gross manual dexterity [40]. 
In conclusion, despite the outstanding development of high-tech devices, their application to pediatric neurorehabilitation and the interesting findings available so far, the key features and optimal control strategies that best enhance neuroplasticity and sensorimotor recovery in children with neurological diseases have not been defined yet and systematic approaches are still scarce. In this framework, the main motivation of this work is to critically review the existing literature related to robot-assisted rehabilitation protocols hitherto developed for the upper limbs of children with neurological disorders, with particular attention to their characteristics, control strategies, application (assessment and/or training) and results in clinical setting. Our specific purpose is to provide a comprehensive perspective on what level of robotic rehabilitation has arrived and which are the most successful methodologies implemented, as to lay the foundations for future studies, to elicit insights into new neuroplasticity-enhancement protocols and to inspire new robot-based approaches.

\section{Materials and Methods}

Scientific articles have been searched according to primary and secondary literature sources. For the secondary literature, it has been searched on the Center for Review and Dissemination (CRD) and on the Cochrane Library, while, for the primary literature, on SCOPUS, PubMed and IEEE Xplore. The literature search has been performed using the following keywords: (pediatric OR child*) AND robot* AND (rehabilitation OR assessment) AND upper AND (limb OR extremit*). Following this preliminary research, it has been carefully checked if the papers found met the following inclusion criteria: (1) robotic devices for the rehabilitation and/or assessment of the upper limbs; (2) devices used for children or young people ( $<18$ years old) with neurological diseases (e.g., CP, Stroke, ABI); (3) studies written in English.

\section{Results}

The results of this review study are presented as follows: overview of the literature search (Section 3.1); detailed analysis of the robotic devices, according to the criteria described in the Materials and Methods section (Section 3.2); safety and usability of robotic devices (Section 3.3); protocols for the robotic assessment of the upper limb functionality (Section 3.4); protocols for robotic rehabilitation of the upper limb (Section 3.5); protocols used to understand motor learning (Section 3.6).

\subsection{Literature Search}

Based on the keywords, no systematic reviews in secondary literature sources were found, while 131 articles were returned from the primary literature databases. Carefully applying the inclusion criteria we selected 38 papers. Among these papers we identified three reviews, three studies only presenting robotics devices and 32 studies on clinical applications (Figure 1 shows the flow diagram that summarizes the process and results of the primary literature search). 


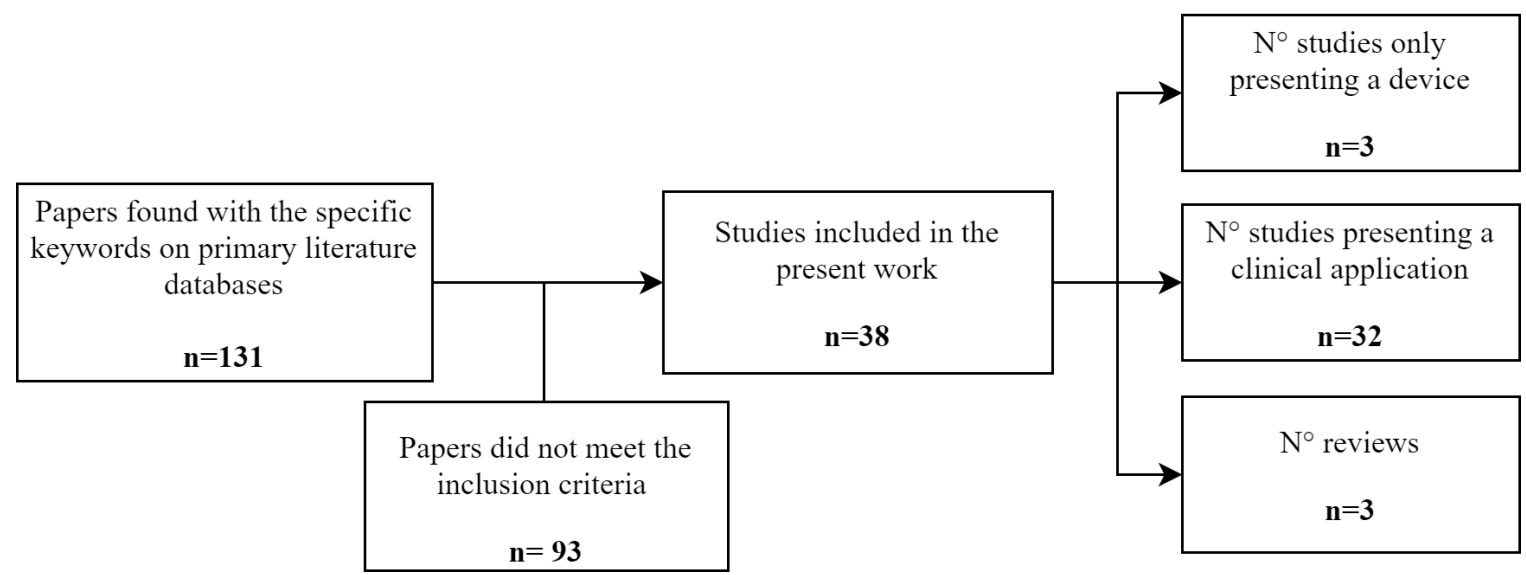

Figure 1. The flow diagram of the number of studies included.

The 3 review papers [41-43] investigated robotic devices for upper limb rehabilitation in children with neurological disorders but with substantial differences from the purposes of the present work:

- Fasoli et al. [41] based their work on a detailed review of the application of one specific robot (InMotion2, later explained) for children with hemiplegia due to CP;

- Chen et al. [42] examined the effectiveness of several upper limb robots applied only to children with CP;

- the third review [43] is focused on clinical protocols performed on children with different neurological diseases but with the use of two specific robots (InMotion2 and NJIT-RAVR).

In the present work we have a more general view and, as described in the introduction section, we aim to analyze and present all the devices and the clinical protocols for upper limb robot-assisted rehabilitation designed for children with neurological disorders (CP, Stroke, ABI).

\subsection{Robotic Devices}

The literature search allowed us to identify a moderate number of robots (14) that were developed beyond the proof-of-concept stage and were actually used for upper limb rehabilitation of children with neurological disorders. In the next paragraphs, the robots are classified following the chronological order of design and briefly described according to some of their relevant features (namely, the type of device, the number of degrees of freedom (DoF) and the affected human joints). Figure 2 shows a graphic map indicating where the 14 selected robots have been developed and actually used. It indicates that, in most of the cases, clinical studies using the robotic devices for pediatric population were performed where the device was designed, with a few notable exceptions. For example Armeo Spring [44], designed in Volketswil (Switzerland) has been primarily used in clinical studies located in Italy; InMotion2 [45], designed at MIT (Boston), has been used also in New York (USA) and Rome (Italy). 


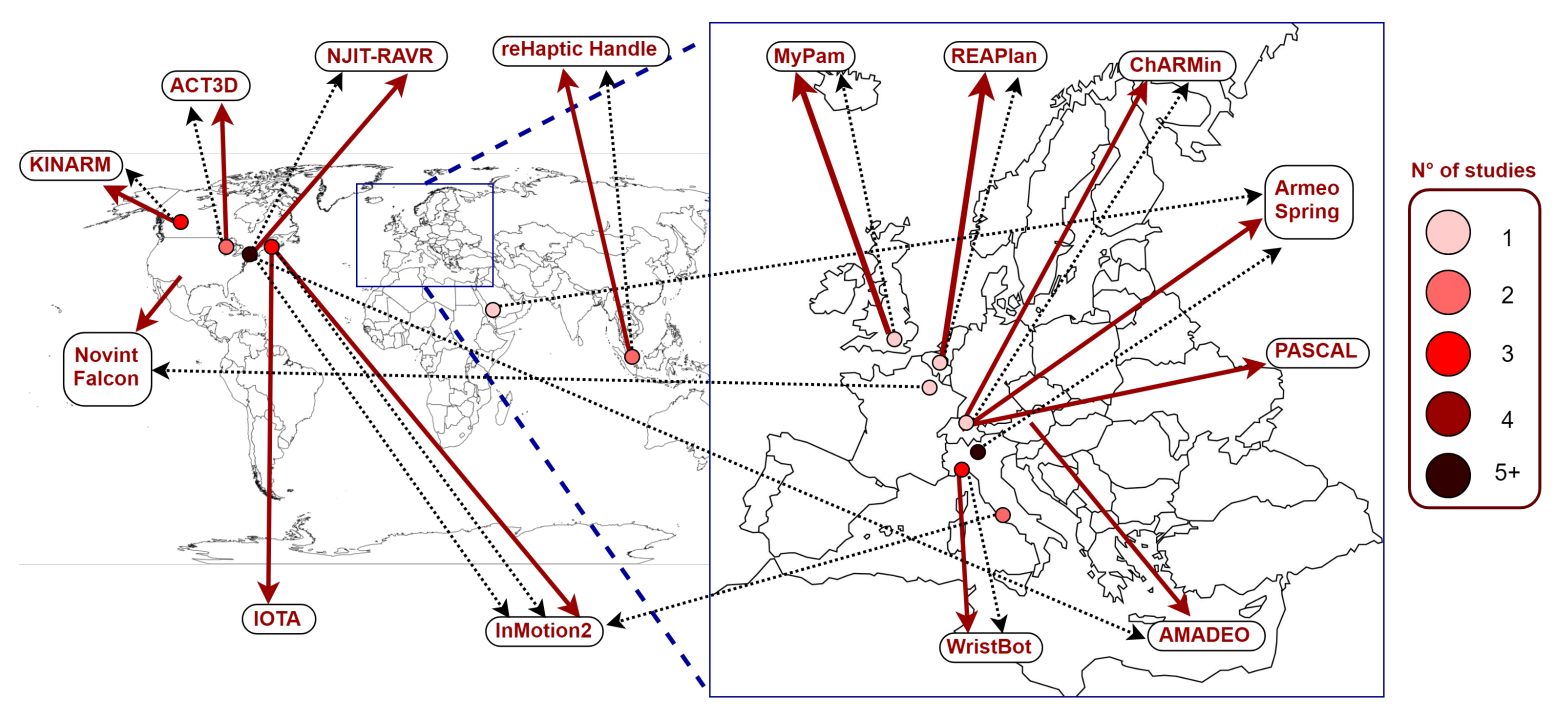

Figure 2. A world map identifying where robots for upper limb rehabilitation have been developed (red arrows) and where they have been used for children with neurological disorders (black dotted arrows). The color filling the circular areas indicates the number of clinical studies performed in the specific locations. The robot selected are:KINARM [46]; ACT3D [47]; NJIT-RAVR [48]; reHaptic Handle [49]; MyPam [50]; REAPlan [15]; ChARMin [51]; Armeo Spring [44]; PASCAL [52]; AMADEO [53]; WristBot [54]; InMotion2 [45]; IOTA [55]; Novint Falcon [56].

The 14 selected devices differ in terms of type (exoskeleton or end-effector) and the sets of targeted joints (shoulder and elbow in most cases, wrist or hand in fewer cases).

As regards the mechanical structure, the selected robots have a different number of degrees of freedom. As regard the control scheme, two schemes are used (impedance control [15,45,51-54] or admittance control [47-49]) that are characterized by specific functional features: robots based on an impedance control scheme are highly backdrivable, thus allowing the users to move actively without being affected by friction and inertia of the device, and operate by measuring accurately the actual position and generating the appropriate force/torque output; in contrast, robots based on the admittance control are generally non-backdrivable, require force/torque sensing and inertia estimation, and operate by sensing the actual interaction force and providing the appropriate position reference as output.

Table 1 stores a systematic presentation of the characteristic features of each selected robotic device. Let us list, here, a brief overview:

1. KINARM [46] is a bimanual robot, which allows movements in the horizontal plane (2 D) targeting the human shoulder and/or elbow joints; it can be used in an exoskeleton or end-effector configuration;

2. InMotion2 [45] is an end-effector robot for shoulder and elbow with 2 DoFs; it is a commercial version of MIT-Manus [57] and its configuration allows low impedance on the horizontal plane and almost infinite impedance on the vertical one;

3. Armeo Spring [44] is an exoskeleton with 5 DoFs with a rehabilitation target of the entire human arm; it is actuated by passive springs with the role of supporting the weight of the arm, allowing natural movements in the $3 \mathrm{D}$ space with a wide range of motion;

4. ACT3D [47] is an end-effector robot that allows movements in 3D space properly designed to treat shoulder and elbow; it consists of a modified 3D HapticMaster (admittance controlled robot for shoulder and elbow) [58] with an instrumented end-effector and the patient's arm is connected to the robot through a lightweight forearm-hand orthosis;

5. NJIT-RAVR [48] is a 6 DoFs end-effector device; it consists of a 3D HapticMaster [58] combined with a ring gimbal that permits 3 additional DoFs (orientation: yam, pitch and rotation: pronation/supination) of the forearm; 
6. WristBot [54] is a 3 DoFs end-effector robot specifically designed to treat wrist and forearm; it provides haptic feedback and compensates for its weight and inertia;

7. Novint Falcon [56] is a 3 DoFs end-effector robot for shoulder and elbow; it was initially created as a computer input device, but later used also in the rehabilitation field;

8. AMADEO [53] is an end-effector robot conceived for the rehabilitation of the hand with $1 \mathrm{DoF}$ for each finger;

9. IOTA [55] is a 2 DoFs exoskeleton that rehabilitates the carpometacarpal (CMC) and metacarpophalangeal (MCP) joints (thumb) needed to perform some of the activities of daily living such as opposition grasp;

10. PASCAL [52] is an end-effector robot for shoulder and elbow treatment with 5 DoFs: 3 DoFs to allow movements in the 3D space (shoulder, elbow) and 2 DoFs to ensure only exchange of interaction forces; in some applications there is the possibility to combine this robot with the Lokomat [59] to allow simultaneous rehabilitation of both upper and lower limbs [60];

11. ChARMin [51,61] is an exoskeleton with 6 DoFs for the entire human arm; it is the first actuated modular pediatric exoskeleton that consists of a proximal part (common for all patients) and a distal one (different depending on the child's age);

12. reHaptic Handle [49] is an end-effector robot with 2 DoFs to train pinching, forearm pronation/supination and wrist flexion/extension movements;

13. REAPlan [15] is a planar end-effector device with $2 \mathrm{DoFs}$ and intended for the rehabilitation of shoulder and elbow;

14. MyPam [50] is a bimanual end-effector robot for shoulder and elbow allowing movements in the horizontal plane; it has been designed to perform rehabilitation in a school environment and it can be used also in unimanual mode.

Table 1. Additional robot features.

\begin{tabular}{|c|c|c|c|c|c|c|c|}
\hline Robot & DOFs & $\begin{array}{c}\text { Rehab } \\
\text { Joint }\end{array}$ & Type & $\begin{array}{c}\text { Output } \\
\text { Measurements }\end{array}$ & Modality & Feedback & $\begin{array}{c}\text { Market } \\
\text { Available }\end{array}$ \\
\hline $\begin{array}{c}\text { KINARM } \\
(1999) \\
{[46]}\end{array}$ & $2+2$ & $\begin{array}{l}\text { Shoulder } \\
\text { elbow }\end{array}$ & End-effector & $\begin{array}{c}\text { Kinesthesia, } \\
\text { position sense, } \\
\text { kinematics }\end{array}$ & $\begin{array}{l}\text { Active; } \\
\text { passive }\end{array}$ & Visual & $\checkmark$ \\
\hline $\begin{array}{c}\text { InMotion2 } \\
\text { (2003) } \\
\text { [45] }\end{array}$ & 2 & $\begin{array}{l}\text { Shoulder } \\
\text { elbow }\end{array}$ & End-effector & Kinematics & $\begin{array}{l}\text { Active; passive; } \\
\text { assistive; } \\
\text { weight support }\end{array}$ & $\begin{array}{c}\text { Visual } \\
\text { haptic } \\
\text { auditory }\end{array}$ & $\checkmark$ \\
\hline $\begin{array}{c}\text { Armeo } \\
\text { Spring } \\
(2004) \\
{[44]}\end{array}$ & 5 & $\begin{array}{l}\text { Shoulder } \\
\text { elbow } \\
\text { forearm } \\
\text { wrist } \\
\text { fingers }\end{array}$ & Exoskeleton & Kinematics & $\begin{array}{c}\text { Active; } \\
\text { weight support }\end{array}$ & $\begin{array}{l}\text { Visual } \\
\text { auditory }\end{array}$ & $\checkmark$ \\
\hline $\begin{array}{c}\text { ACT3D } \\
(2007) \\
{[47]}\end{array}$ & 3 & $\begin{array}{l}\text { Shoulder } \\
\text { elbow }\end{array}$ & End-effector & $\begin{array}{l}\text { Kinematics, } \\
\text { Forces }\end{array}$ & $\begin{array}{l}\text { Active; passive; } \\
\text { weight support }\end{array}$ & $\begin{array}{l}\text { Visual } \\
\text { haptic } \\
\text { auditory }\end{array}$ & \\
\hline $\begin{array}{c}\text { NJIT-RAVR } \\
(2009) \\
{[48]}\end{array}$ & 6 & $\begin{array}{l}\text { Shoulder } \\
\text { elbow } \\
\text { forearm }\end{array}$ & End-effector & $\begin{array}{c}\text { Kinematics, } \\
\text { RoM }\end{array}$ & $\begin{array}{c}\text { Active; } \\
\text { assistive; } \\
\text { resistive; } \\
\text { weight support }\end{array}$ & $\begin{array}{l}\text { Visual } \\
\text { haptic } \\
\text { auditory }\end{array}$ & \\
\hline $\begin{array}{c}\text { WristBot } \\
(2009) \\
{[54]}\end{array}$ & 3 & $\begin{array}{l}\text { Forearm } \\
\text { wrist }\end{array}$ & End-effector & $\begin{array}{l}\text { Kinematics, } \\
\text { wrist RoM }\end{array}$ & $\begin{array}{l}\text { Active; passive; } \\
\text { assistive; } \\
\text { weight support }\end{array}$ & $\begin{array}{l}\text { Visual } \\
\text { hapitc } \\
\text { auditory }\end{array}$ & \\
\hline $\begin{array}{c}\text { Novint } \\
\text { Falcon } \\
(2009) \\
{[56]}\end{array}$ & 3 & $\begin{array}{l}\text { Shoulder } \\
\text { elbow } \\
\text { forearm }\end{array}$ & End-effector & Kinematics & $\begin{array}{l}\text { Active; } \\
\text { assistive }\end{array}$ & $\begin{array}{l}\text { Visual } \\
\text { auditory } \\
\text { haptic }\end{array}$ & $\checkmark$ \\
\hline
\end{tabular}


Table 1. Cont.

\begin{tabular}{|c|c|c|c|c|c|c|c|}
\hline Robot & DOFs & $\begin{array}{l}\text { Rehab } \\
\text { Joint }\end{array}$ & Type & $\begin{array}{c}\text { Output } \\
\text { Measurements }\end{array}$ & Modality & Feedback & $\begin{array}{c}\text { Market } \\
\text { Available }\end{array}$ \\
\hline $\begin{array}{c}\text { AMADEO } \\
(2011) \\
{[53]}\end{array}$ & 5 & Fingers & End-effector & $\begin{array}{l}\text { Magnitude and } \\
\text { directionality } \\
\text { of the forces }\end{array}$ & $\begin{array}{l}\text { Active; passive; } \\
\text { assistive }\end{array}$ & $\begin{array}{l}\text { Visual } \\
\text { haptic }\end{array}$ & $\checkmark$ \\
\hline $\begin{array}{c}\text { IOTA } \\
(2013) \\
{[55]}\end{array}$ & 2 & Thumb & Exoskeleton & $\begin{array}{l}\text { Wrist RoM, } \\
\text { angular rotation } \\
\text { of the thumb }\end{array}$ & $\begin{array}{l}\text { Active; passive; } \\
\text { assistive }\end{array}$ & $\begin{array}{l}\text { Visual } \\
\text { haptic }\end{array}$ & \\
\hline $\begin{array}{c}\text { PASCAL } \\
(2013) \\
{[52]}\end{array}$ & $3+2$ & $\begin{array}{l}\text { Shoulder } \\
\text { elbow }\end{array}$ & End-effector & $\begin{array}{l}\text { End-effector } \\
\text { kinematics }\end{array}$ & $\begin{array}{l}\text { Active; passive; } \\
\text { assistive; } \\
\text { weight support }\end{array}$ & $\begin{array}{l}\text { Visual } \\
\text { haptic }\end{array}$ & \\
\hline $\begin{array}{c}\text { CHARMin } \\
\text { (2013) } \\
{[51]}\end{array}$ & 6 & $\begin{array}{l}\text { Shoulder } \\
\text { forearm } \\
\text { wrist }\end{array}$ & Exoskeleton & $\begin{array}{c}\text { Arm } \\
\text { kinematics }\end{array}$ & $\begin{array}{c}\text { Active; passive; } \\
\text { assistive; } \\
\text { weight support }\end{array}$ & $\begin{array}{c}\text { Visual } \\
\text { haptic } \\
\text { auditory }\end{array}$ & \\
\hline $\begin{array}{c}\text { ReHaptic } \\
\text { Handle } \\
(2014) \\
{[49]}\end{array}$ & 2 & $\begin{array}{l}\text { Forearm } \\
\text { wrist }\end{array}$ & End-effector & $\begin{array}{l}\text { Grip forces, } \\
\text { kinematics, } \\
\text { wrist RoM }\end{array}$ & $\begin{array}{l}\text { Active; passive } \\
\text { assistive; } \\
\text { resistive } \\
\text { weight support }\end{array}$ & $\begin{array}{l}\text { Visual } \\
\text { haptic }\end{array}$ & \\
\hline $\begin{array}{c}\text { REAPlan } \\
(2015) \\
{[15]}\end{array}$ & 2 & $\begin{array}{c}\text { Shoulder } \\
\text { elbow }\end{array}$ & End-effector & $\begin{array}{l}\text { End-effector } \\
\text { kinematics }\end{array}$ & $\begin{array}{l}\text { Active, passive, } \\
\text { assistive }\end{array}$ & $\begin{array}{c}\text { Visual } \\
\text { haptic } \\
\text { auditory }\end{array}$ & $\checkmark$ \\
\hline $\begin{array}{c}\text { MyPam } \\
(2015) \\
{[50]}\end{array}$ & 2 & $\begin{array}{l}\text { Shoulder } \\
\text { elbow }\end{array}$ & End-effector & Kinematics & $\begin{array}{l}\text { Active; } \\
\text { assistive }\end{array}$ & $\begin{array}{l}\text { Visual } \\
\text { haptic }\end{array}$ & \\
\hline
\end{tabular}

\subsection{Safety and Usability of Robotic Devices}

In the field of robot-assisted rehabilitation, the safety of the robotic device must be ensured. In particular, this represents a very crucial aspect because the patients interact physically with the robots and, generally, they are not able to retract their arm when a critical situation occurs. For this reason, hard safety measures in terms of hardware and software adjustments must be taken. For example, at software level, many devices (Armeo Spring [44], AMADEO [53], Novint Falcon [56], ChARMin [51]) reported the implementation of algorithms to limit the range of motion, the force exerted and/or the speed generated on the arm of the patients. Regarding the InMotion 2 [45], the backdrivability of the device has been cited as safety feature. It is worth mentioning that, even if not explicitly reported on the selected papers, the robotic devices used in the rehabilitation domain, need to implement basic safety features as requested by international regulations. In order to be more precise, we decided to consider three categories: (1) commercial robots; (2) prototypes used in clinical studies; (3) prototypes not already used in clinical studies. The devices belonging to the first category are identified in the "Market available" column of Table 1. In order to obtain the medical certification and then the authorization to be commercialized, these devices must address all the safety features requested by law. In this same way, considering the prototypes used in the clinical studies, they should have implemented the same safety features of the commercial ones in order to be authorized by the Institutional Review Committee (IRB) for the use with human subjects. However, for the third category, the safety mechanisms should be reported in the papers. Indeed, the IOTA device presents an emergency stop button that immediately arrests the motors if pressed [55], while, the PASCAL has brakes that block movements in the horizontal axes and a magnetic release that disconnects the robot from the power in case of emergency [60].

Another remarkable aspect is the concept of the usability of a robotic device for rehabilitation. Firstly, the robot should ensure a high level of comfort for the user. In this regard, in general, it has been shown [62] that an end-effector robot is more flexible than an exoskeleton in fitting different sizes of body parts, reducing setup time and increasing ease of use for new patients. Moreover, there is some minimal information on the usability of some of the selected devices: the IOTA is drawn 
to be lightweight and fit children aged 7 to 12 years old [55] while the ChARMin has two different modules to best fit and cover the range of patients aged 5 to 18 years old [63]. Another aspect is related to the operator point of view: the robot should be properly designed to be easily applied on patients, reducing the cognitive load of the operator itself. The operator should supervise the therapy, monitor the patient's safety, set the protocol and adjust its parameters according to the child's level of impairment.

Finally, we want to emphasize what is missing in most of the selected studies: the safety and usability perceived by the operator and the patient. Indeed, we found only three studies $[45,63,64]$ in which researchers asked, through a questionnaire, the acceptance and tolerance of the device (InMotion2, ChARMin) to therapists and end-users (e.g., children or their parents).

\subsection{Robotic Protocols for Upper Limb Assessment}

In this section, we reviewed how robotic devices have been used for the functional evaluation of upper limbs performance, improving and extending the explanatory power of the already mentioned clinical scales. As it is well known, clinical scales performed by therapists are the accepted method for evaluating the motor performance of patients. But, although they are widely used in the clinical setting, they are operator-dependent, have little sensitivity to detect small changes in improvement over time and are time-consuming to apply [65]. In contrast, the possibility of a quantitative and reliable description of motor performance is intrinsic in the design, the control, and the actual usage of robotic devices. As a consequence, the robotic assessment of performance can provide high temporal and spatial resolution measurements that allow recording position, velocities and forces of the joints and obtain from them kinematic, kinetic and dynamic parameters [66]. In particular, the following studies have shown that robotic devices can provide quantitative, accurate, repeatable and sensitive assessment. Robotic assessment means the evaluation of specific measurements (kinematics, RoM: Range of Motion, smoothness) through dedicated assessment tasks, before, possibly during, and after the rehabilitation treatment in order to estimate the effectiveness of robotic rehabilitation. Specifically, robotic evaluation could reduce assessment time, detect even small changes, thus representing a powerful tool for physiotherapists to capture delays in motor development and track children's progress over time [32]. These quantitative measures can be added to clinical scales to help the physiotherapist to draw up a more complete clinical picture of the patients and modify the clinical protocol based on their needs.

In some of the reviewed studies, robotic devices have been applied to extract kinematic and dynamic measurements directly from the data collected by the robot before, during and after the rehabilitation training; conversely, in some other studies the robot had been specifically designed as a tool for the assessment and was used to measure upper limb sensorimotor functions, independently from the training.

More specifically, in the first group, the NJIT-RAVR has been used to evaluate the hand movement speed, movement duration, smoothness and range of motion [67-69]; the WristBot and the reHaptic Handle have been used to quantify the maximum range of motion of the wrist $[49,70,71]$; the InMotion 2 and REAPlan devices have been used to evaluate the straightness, speed and smoothness of trajectories in specific reaching activities [15,24]; and additionally, InMotion 2 has also been used in a multi-joint planar task requiring coordination of the shoulder and elbow joint in order to assess the upper limb motor performance after injections of botulinum toxin type A (BTX-A) in children with hemiplegia due to $\mathrm{CP}$ or $\mathrm{ABI}$ [64]. Moreover, the MyPam robot has been used to evaluate motor performance in reaching tasks, demonstrating neurological enhancement through maintaining and improving motor skills in the washout period after robotic training in children with CP [50].

Conversely, the KINARM robot is a device specifically designed as a robotic tool for the assessment. This device allowed to quantify position sense and kinesthesia [72] in hemiparetic children with perinatal stroke showing how the location of neurological damage differently defines proprioceptive deficits [73]. Additionally, Kuczynski et al. used this device to quantify bilateral motor impairments in 
hemiparetic children with unilateral perinatal stroke; they have confirmed that an unilateral injury can lead to bilateral motor disabilities, suggesting to rehabilitate both controlateral and ipsilesional limb [74].

\subsection{Robotic Protocols for Upper Limb Rehabilitation}

Here we present the robotic protocols related to each robot and performed by children in the selected clinical studies, emphasizing the characteristics of the treatments and their results. Table 2 summarizes the fundamental features of the clinical studies.

The InMotion 2 is based on performance and impedance-based control strategies. Typically, the levels of assistance are triggered according to three parameters: (1) the speed of the end-effector (when the child's arm speed exceeds a certain threshold), (2) the recorded EMG activation (when at least one of the recorded muscles overcomes a threshold) or (3) the elapsed time from the prompt stimulus delivery (when the child is not able to move the handle within a fixed time period) [75]. Such three parameters are not only used to trigger robotic assistance, but also constantly measured to continuously modulate the robotic assistance according to child's performance and to make the rehabilitation adaptive and progressive. In particular, we quote 7 clinical studies involving this device $[14,21,26,76-80]$. In one study [76], the robot was used to show the different responses of healthy children and pediatric patients to perturbing force fields: specifically, healthy subjects tend to learn to compensate for perturbed forces and consequently predict the force field; in contrast, children affected by weakness and spasticity due to $\mathrm{CP}$, show a limitation of brain capacity to calibrate the sensorimotor system. This effect also implies the difficulty of creating an anticipatory strategy to counteract a deviation of force field [76] and thus a reliable internal prediction model [77]. Frascarelli et al. [26] have shown that the use of the InMotion 2 for the rehabilitation of children with neurological disorders $(\mathrm{CP}, \mathrm{ABI})$ had a great benefit, as it could drastically improve both clinical and robotic measures. Additionally, Fasoli et al. [14] have demonstrated that the robotic training with the device for children with hemiplegia due to $\mathrm{CP}$ or $\mathrm{ABI}$ showed improvements in coordination of upper limb and quality of movement with a low impact on spasticity and muscle strength, and also a slight improvement in distal dexterity. In another study, Fasoli et al. [78] have investigated the effectiveness of the robot-assisted therapy following BTX-A injections to reduce spasticity in elbow, wrist and finger flexors in a child with CP. They showed that, at the end of the training, the child decreased muscle tone, improved upper limb coordination and quality of movement while the strength remained the same, concluding that these outcomes were similar to those obtained after conventional occupation therapy combined with injections of BTX-A. Moreover, Turner et al. [79] confirmed also the benefits of using robotic therapy in children affected by stroke. More specifically, they compared the reactions to InMotion 2 robotic training of pediatric stroke patients with those of adult stroke population undergoing early robotic-assisted therapy. They showed a slower rate of improvement of the FMA scale in children than in adults, with the highest growth in the first 3 months. Another study with this device concerned the comparison between the sequential (predictable) and random (unpredictable) modes of administration of the exercises during training [21]: the researchers have shown no significant differences between them. The random group required higher level of attention during the treatment without any immediate improvement but with greater gains at the six-monthly evaluation; the sequential group showed better initial results with the acquired values that remained unchanged over time. The last study [80] concerns the development of an approach based on data extraction in the initial phase of the training session with InMotion2. The aim of this method was to understand the patient's learning rate, to predict his/her progress and to design a more customized rehabilitation protocol according to his/her needs. To accomplish this purpose, the researchers acquired kinematic and kinetic data of children with CP during the robot-assisted assessment; these data were labeled by the QUEST and the gradient of improvement change in the QUEST between the baseline and one-month follow-up and were subjected to the K-means clustering. 
Armeo Spring is based on weight counterbalancing assistance as it supports the weight of the upper limbs through its springs. This device records movement parameters such as resistance, strength, coordination and range of motion and is adjustable according to the patient's condition. We found 7 clinical studies involving this device [81-87]. It has been used primarily for clinical rehabilitation protocols for children with $\mathrm{CP}$, demonstrating a better quality of upper limb movements due to improvements of QUEST and MAAULF scales at the end of the training [81-83]. Nonetheless, we also found a study showing that the training with Armeo improved only the MAAULF scale while the QUEST scale remained unchanged, which means improvements in functional gains of the upper limbs and not in the movement characteristics [84]. However, significant improvements in terms of QUEST scale after the training with Armeo has been proven by El-Shamy [85], showing that robotic-assisted therapy is more effective than conventional therapy in promoting functional improvements of upper limbs, suggesting to combine conventional and robotic therapies for the achievement of better rehabilitation gains. In support of this thesis, another study [82] has demonstrated the improvement of functionality of the upper limbs after Armeo Spring training in children with CP and ABI. However, the researchers have noticed that the recovery was different between the two groups and that children with $\mathrm{ABI}$ improved essentially in the first period of training whereas children with $\mathrm{CP}$ in the second one. Due to this different responses to the same treatment, authors suggested the need to differentiate the rehabilitative protocol according to the neurological disorders. In another study, Beretta et al. [86] trained children with ABI with different approaches: CIMT (Constraint-Induced Movement Therapy), PT (physical therapy), Armeo Spring with the purpose to characterize the possible different outcomes. It turned out that CIMT treatment emerged as the most effective in improving the proximal movements, specifically at the shoulder joints, PT promoted an improvement in the distal movements and increased the speed and fluidity of fingers, while the Armeo Spring therapy elicited improvements in shoulder RoM in abduction/adduction but it worsened performance in flexion/extension. According to the authors, this negative effect was related to mechanical constraints imposed by the exoskeleton during the training. Finally, they concluded that these approaches are complementary and could be used together to train children with ABI. In a further study with Armeo Spring, Peri et al. [87] calculated an index of performance consistent with the MAS score using the data collected by the robot such as the completion time, the score obtained and the level of difficulty.

$A C T 3 D$ uses weight counterbalancing assistance as it provide a virtual effect of gravity, that is progressively modulated according to the participant's impairments and that can be enhanced or reduced by imposing forces along its vertical axis. We found only one study involving the ACT3D in children with neuromotor disorders [88]. Clinically, it is possible to associate upper limb movements in children with spastic hemiparetic cerebral palsy with those of adults who have had a stroke. For this reason, firstly, Sukal et al. [89] have conducted a study using the ACT3D device to investigate the response of arm movements of stroke adults under dynamic conditions. In addition, they have studied [88] its application on a population of children with CP in order to understand the nature of their movement deficits. They have concluded that, based on the trajectories recorded by the robot, it could be easier to capture the expression of the abnormal movements, and, in addition, the robot could be used to train children with CP to overcome the negative effect of those [88].

NJIT-RAVR uses performance-based and weight counterbalancing assistance control strategy. The assistive mode consists of gradually increasing an haptic spring that pushes the subject towards the target if the speed or the subject's force does not reach a minimum thresholds. We found three studies involving this device [67-69]. All of them have established the feasibility of combining robotics with rich virtual environment to decrease motor impairments in children with mild to moderate hemiplegia secondary to cerebral palsy and the possibility of integrating it with other clinical therapies without any adverse responses $[67,68]$. In addition, it has been shown that children's motivation during training remained high, generating a good patient response to training with great improvements in the active RoM of the upper limbs, in both kinematics and motor performance at the end of the training [69]. 
WristBot uses performance and impedance-based control strategies implemented as a nonlinear elastic force field with a parabolic profile: for small errors, the slope of the assistance is less than linear whereas for large errors, assistance grows more than linear to speed up the learning process. This nonlinear profile is consistent with the assist-as-needed principle, according to which assistance forces must remain low to promote the onset of voluntary control. We found three studied involving the WristBot device $[70,71,90]$. All of them proposed a therapeutic approach based on tracking tasks in which the level of the assistive force field was adjusted online according to the distance between the target and the end-effector position: the greater this distance, the higher was robotic assistance. At the end of the training, Marini et al. $[70,90]$ have proved that improvements in subjects' kinematics (such as coordination and motor skills) were strongly correlated with the reduction of the robotic intervention and hence to a greater active control of the patient's wrist. Furthermore, another study using the WristBot [71] has modulated the assistance level depending on subject's speed: if the speed of the subject was too slow, the intensity was increased linearly; but as soon as his/her speed increased, the assistive force remained constant to facilitate the voluntary movement of the subject. This study proved that an intensive distal upper limbs robotic rehabilitation improved active wrist RoM, wrist kinematics and dynamics and it led to improvements in both proximal and distal parts of the upper limbs in a pediatric stroke patient.

Novint Falcon uses an impedance-based control strategy that consists in a resist-as-needed (tunneling) configuration, in which the children were free to move along the required path in a virtual reality environment but, as they converged on alternative trajectories, the device generated a force feedback to push them to the desired path. Only one clinical study involving this device was found. Specifically, Elsaeh et al. [28] trained the shoulder abduction/adduction and flexion/extension and forearm pronation/supination of two children with $\mathrm{CP}$ using this device. At the end of the training, they presented an improvement of the joints motion of upper limbs, by showing a lower number of interaction with the force feedback of the device (meaning more accurate movements) and a higher number of objects collected during the exercises (meaning greater speed).

$A M A D E O$ can be used in different conditions depending on the patient's impairment: passive, active and assistive. Each grasping movement can be controlled through different trigger signals (such as isometric force, range of motion or surface electromyography) in order to train different functional activities [91]. The only study found with this device was carried out by Bishop et al. [92] and they showed that the device led to an improvement in children with hemiparesis especially in their trained distal part (e.g., grip and opening of the hand), compared to their untrained proximal part. As suggested, a way to fill this gap and get better gains could be to combine this device with other systems designed for the rehabilitation of the proximal joints of the upper limbs.

IOTA includes different possible control modes: active; wrist control mode and triggered assistance which is useful for people with small voluntary movements of their thumb. Specifically, the robot is able to monitor the orientation of the patient's thumb and judge the identity of the movement, i.e. if it considers the movement greater than a minimum threshold but still weak, then it amplifies the movement by generating a greater response motion. Even though, to our knowledge, no clinical protocols exists using IOTA.

PASCAL is based on the assist-as-needed control strategy, in which the robot helps the patient reaching the target with an amount of assistance that is proportional to subject's needs. The assist-as-needed strategy is organized as follows: first, with the creation of a virtual haptic tunnel aligned with a desired ideal trajectory and implemented with a force field that repulses the subject's hand from the walls of the tunnel; second, with the identification of the minimum/maximum speed thresholds to proceed along the path and the increase of the force supports when the speed is below the threshold and vice versa; third, with the introduction of a direction-dependent supportive flux consisting of an adaptable force that assists the patients moving along the virtual tunnel; and finally, with a gain-scheduling impedance control that attracts the end-effector to the target position if the subject is unable to reach it. It has been shown that the assistance of this device can move from full 
assistance (i.e. when the subject is severely impaired) to lack of assistance (i.e. when the subject can achieve the reaching task without problems) [52].

ChARMin is based on a control strategy similar to the one used in the PASCAL device. It consists of a virtual haptic tunnel, representing the ideal trajectory to be followed from the starting to the target position, with the identification of the minimum/maximum speed threshold to proceed along the path. In the literature, we found only a clinical study that has tested the feasibility of rehabilitation with the ChARMin device on children with neurological disorders, adapting the difficulty of the exercises and the assistance of the robot to the capabilities of the patient [63].

reHaptic Handle uses a weight counterbalancing assistance and it is applied in an assistive or resistive mode; it records the forces/torques exerted by the patient and computes the position or velocity of the end-effector, providing assistance for the forearm rotation and hand opening/closing. The reHaptic Handle was involved in one clinical study and it has been used to train the upper limb functions of a child with mild disabilities. Moreover, Tong et al. [93] have shown that the robotic-assisted therapy improved movement speed, accuracy, smoothness and changes in movement patterns (more straight movements).

REAPlan uses a performance and impedance-based control strategies; it records the interaction forces between the patient and the robot, which are the lateral and longitudinal force. The first is the force perpendicular to the ideal trajectory that pushes the patient to move on the desired path, and the second is the force parallel to the ideal trajectory that helps the patient to move along the trajectory at fixed speed. The higher these forces, the more the robot assists the subject in the execution of the task and in avoiding the choice of different paths. Additionally, at the end of each trial, these forces are adapted to the patient's performance and the subject receives information about his trajectory in real time through visual feedback. Only one clinical study has been found involving the REAPlan device. In this study, Gilliaux et al. [15] used this device to compare robot-assisted therapy with conventional therapy in children with PC. As a result of the training the first group presented a greater smoothness and a higher manual dexterity than the group that underwent conventional therapy; however, there was no generalization of motor skills to more functional activities not directly linked to training tasks.

To conclude this paragraph, we noticed that only five clinical protocols used a control group to evaluate the effects of the robot-assisted rehabilitation. Specifically, two clinical studies $[81,83]$ enrolled healthy children as control group trying to understand the difference between the performance of impaired children, after robotic rehabilitation, and healthy age-matched controls. Two other studies $[15,85]$ used, as control group an age-matched population affected by the same neurological disorder undergoing conventional therapy. Finally, another clinical protocol [68] used, as control group, children with the same neurological disorder undergoing robotic therapy in combination with other treatments, demonstrating the feasibility of this approach without adverse effects.

\subsection{Motor Learning in Robot-Assisted Therapy}

In this section, we consider two clinical studies involving robot-assisted therapy for motor habilitation in children with CP. These studies showed whether motor learning has occurred through its three conventional main stages, namely (1) skill acquisition, (2) generalization, and (3) retention. More specifically, in a first study, children were asked to perform assisted point-to-point movements using the InMotion2. At the end of the training participants showed good ability in generalization of acquired skills, emerged from the test of untrained movements (e.g., circle-drawing), and in retention, emerged from the persistence of acquired motor skills one month after the end of training [24]. In the second study, the robotic training with the Armeo Spring device elicited an increase in both the task performance and the BBT score, suggesting promotion of skill acquisition and generalization with the retention of these results one day (or, when possible, 7 days) after the end of the training [94].

Based on these considerations, the motor learning in children with CP may occur when the most affected arm is trained with an end-effector device or in a rich and playful virtual environment using an exoskeleton. 
Table 2. Clinical protocols. nP: number of patients; nCG: number of control group subjects. ${ }^{a}$ indicates the age range.

\begin{tabular}{|c|c|c|c|c|c|c|c|c|c|}
\hline $\begin{array}{l}\text { Robot, } \\
\text { Study }\end{array}$ & $\begin{array}{c}\text { nP, } \\
\text { Mean Age } \\
( \pm \text { SD })\end{array}$ & $\begin{array}{l}\text { Diagnosis, } \\
\text { Mean Age at } \\
\text { Injury }( \pm S D)\end{array}$ & $\begin{array}{l}\text { nCG, } \\
\text { Mean Age } \\
( \pm \text { SD })\end{array}$ & $\begin{array}{l}\text { Duration } \\
\text { [Weeks] }\end{array}$ & $\begin{array}{c}n \\
\text { Sessions } \\
\text { for Day }\end{array}$ & $\begin{array}{l}\text { Intensity } \\
\text { [min/ses] }\end{array}$ & $\begin{array}{l}\text { Clinical } \\
\text { Assessment }\end{array}$ & $\begin{array}{c}\text { Robotic } \\
\text { Assessment }\end{array}$ & Results \\
\hline $\begin{array}{l}\text { InMotion2 } \\
{[14]}\end{array}$ & $\begin{array}{c}12, \\
9.2(2.1)\end{array}$ & $\begin{array}{l}\mathrm{CP} \\
\mathrm{ABI}\end{array}$ & No & $\begin{array}{c}8 \\
2 \text { days/week }\end{array}$ & 1 & 60 & $\begin{array}{l}\text { QUEST } \\
\text { MAS } \\
\text { FMA }\end{array}$ & Kinematics & $\begin{array}{l}\text { - Strong improvement of QUEST and FMA } \\
\text { - Moderate effect in MAS }\end{array}$ \\
\hline $\begin{array}{l}\text { InMotion2 } \\
{[26]}\end{array}$ & $\begin{array}{c}12, \\
11.7(3.1)\end{array}$ & $\begin{array}{c}\text { CP } \\
\text { Stroke } \\
\text { ABI, } \\
2.9(2.7) \\
\end{array}$ & No & $\begin{array}{c}6 \\
3 \text { days/week }\end{array}$ & 1 & 60 & $\begin{array}{l}\text { MAS } \\
\text { FMA } \\
\text { MAAULF }\end{array}$ & $\begin{array}{l}\text { Kinematics } \\
\text { Smoothness }\end{array}$ & $\begin{array}{l}\text { - Higher smoothness } \\
\text { - Better shoulder-elbow connection }\end{array}$ \\
\hline $\begin{array}{l}\text { InMotion2 } \\
\text { [24] }\end{array}$ & $\begin{array}{c}12, \\
{[5,12]^{\text {a }}}\end{array}$ & $\begin{array}{l}\mathrm{CP} \\
\mathrm{ABI}\end{array}$ & No & $\begin{array}{c}8 \\
2 \text { days/week }\end{array}$ & 1 & 60 & $\begin{array}{l}\text { QUEST } \\
\text { MAS } \\
\text { FMA }\end{array}$ & Kinematics & $\begin{array}{l}\text { - Higher smoothness } \\
\text { - Improvement of kinematics }\end{array}$ \\
\hline $\begin{array}{l}\text { InMotion2 } \\
\quad[21]\end{array}$ & $\begin{array}{c}31 \\
8.2(0.0)\end{array}$ & $\begin{array}{l}\mathrm{CP} \\
\mathrm{ABI} \\
6\end{array}$ & No & $\begin{array}{c}8 \\
2 \text { days/week }\end{array}$ & 1 & 60 & $\begin{array}{l}\text { MAS } \\
\text { FMA }\end{array}$ & $\backslash$ & $\begin{array}{l}\text { - Significant improvement of FMA in } \\
\text { both the random and sequential groups } \\
\text { - No differences between groups }\end{array}$ \\
\hline $\begin{array}{l}\text { InMotion2 } \\
\text { [79] }\end{array}$ & $\begin{array}{c}1, \\
17.0(0.0)\end{array}$ & $\begin{array}{c}\text { ABI, } \\
17.0(0.0)\end{array}$ & No & $\begin{array}{c}36 \\
2 \text { days/week }\end{array}$ & 1 & 60 & FMA & 1 & $\begin{array}{l}\text { - FMA score is greatest over the first } 3 \text { months } \\
\text { - the increase of FMA is slower in the } \\
\text { child patient than in an adult stroke patient }\end{array}$ \\
\hline $\begin{array}{l}\text { Armeo } \\
\text { Spring } \\
{[84]}\end{array}$ & $\begin{array}{c}10 \\
10.9(2.3)\end{array}$ & $\begin{array}{l}\mathrm{CP} \\
\mathrm{ABI}\end{array}$ & No & $\begin{array}{c}4 \\
2 \text { days/week }\end{array}$ & 1 & 45 & $\begin{array}{l}\text { QUEST } \\
\text { MAS } \\
\text { MAUULF }\end{array}$ & RoM & $\begin{array}{l}\text { - Significant improvement of MAUULF } \\
\text { - QUEST remained the same } \\
\text { - No improvement for hand and fingers dexterity }\end{array}$ \\
\hline $\begin{array}{l}\text { Armeo } \\
\text { Spring } \\
{[81]}\end{array}$ & $\begin{array}{c}8, \\
{[6,14]^{\mathrm{a}}}\end{array}$ & $\mathrm{CP}$ & $\begin{array}{l}10 \\
\text { healthy } \\
{[7,14]^{\mathrm{a}}}\end{array}$ & $\begin{array}{c}4 \\
5 \text { days/week }\end{array}$ & 2 & 45 & $\begin{array}{l}\text { QUEST } \\
\text { MAUULF }\end{array}$ & 1 & $\begin{array}{l}\text { - Improvement of clinical scales } \\
\text { - Improvement of kinematic evaluation }\end{array}$ \\
\hline $\begin{array}{l}\text { Armeo } \\
\text { Spring } \\
{[85]}\end{array}$ & $\begin{array}{c}15 \\
6.9(0.8)\end{array}$ & $\mathrm{CP}$ & $\begin{array}{c}15 \\
\mathrm{CP} \\
6.8(0.8)\end{array}$ & $\begin{array}{c}12 \\
3 \text { days/week }\end{array}$ & 1 & 45 & $\begin{array}{l}\text { QUEST } \\
\text { MAS }\end{array}$ & 1 & $\begin{array}{l}\text { - Significant improvement of MAS and QUEST } \\
\text { in the group of robotic rehabilitation }\end{array}$ \\
\hline $\begin{array}{l}\text { Armeo } \\
\text { Spring } \\
{[86]}\end{array}$ & $\begin{array}{c}18, \\
12.3(5.1)\end{array}$ & $\begin{array}{c}\text { Stroke } \\
\text { ABI, } \\
10.9(4.9)\end{array}$ & No & $\begin{array}{c}4 \\
5 \text { days/week }\end{array}$ & 1 & 45 & $\begin{array}{l}\text { QUEST } \\
\text { MAAULF }\end{array}$ & 1 & $\begin{array}{l}\text { - Improvement of MAUULF } \\
\text { - Improvement of the shoulder abd/add and } \\
\text { reduction of the shoulder flex/ext }\end{array}$ \\
\hline $\begin{array}{l}\text { Armeo } \\
\text { Spring } \\
{[82]}\end{array}$ & $\begin{array}{c}43, \\
11.1(5.8)\end{array}$ & $\begin{array}{c}\mathrm{CP} \\
\mathrm{ABI} \\
10.0(8.9)\end{array}$ & No & $\begin{array}{c}4 \\
5 \text { days/week }\end{array}$ & 1 & 45 & $\begin{array}{l}\text { QUEST } \\
\text { MAUULF }\end{array}$ & $\begin{array}{l}\text { Kinematics } \\
\text { Smoothness }\end{array}$ & $\begin{array}{l}\text { - Improvement of MAUULF and QUEST for } \\
\text { both CP and ABI children } \\
\text { - Improvement of the kinematic values } \\
\text { - More improvements in ABI than in CP }\end{array}$ \\
\hline $\begin{array}{l}\text { Armeo } \\
\text { Spring } \\
{[83]}\end{array}$ & $\stackrel{21,}{[7,14]^{\mathrm{a}}}$ & $\mathrm{CP}$ & $\begin{array}{l}15 \\
\text { healthy } \\
{[7,14]^{\mathrm{a}}}\end{array}$ & $\begin{array}{c}4 \\
5 \text { days/week }\end{array}$ & 2 & 45 & $\begin{array}{l}\text { QUEST } \\
\text { MAUULF }\end{array}$ & 1 & $\begin{array}{l}\text { - Improvement of MAAULF and QUEST } \\
\text { - Improvement of the kinematics } \\
\text { - No improvement for upper limb RoMs }\end{array}$ \\
\hline
\end{tabular}


Table 2. Cont.

\begin{tabular}{|c|c|c|c|c|c|c|c|c|c|}
\hline $\begin{array}{l}\text { Robot, } \\
\text { Study }\end{array}$ & $\begin{array}{c}\mathrm{nP}, \\
\text { Mean Age } \\
( \pm \mathrm{SD})\end{array}$ & $\begin{array}{c}\text { Diagnosis, } \\
\text { Mean Age at } \\
\text { Injury ( } \pm \text { SD) }\end{array}$ & $\begin{array}{c}\text { nCG, } \\
\text { Mean Age } \\
( \pm \text { SD })\end{array}$ & $\begin{array}{l}\text { Duration } \\
\text { [Weeks] }\end{array}$ & $\begin{array}{c}n \\
\text { Sessions } \\
\text { for Day }\end{array}$ & $\begin{array}{l}\text { Intensity } \\
{[\mathrm{min} / \mathrm{ses}]}\end{array}$ & $\begin{array}{l}\text { Clinical } \\
\text { Assessment }\end{array}$ & $\begin{array}{l}\text { Robotic } \\
\text { Assessment }\end{array}$ & Results \\
\hline $\begin{array}{l}\text { Armeo } \\
\text { Spring } \\
{[94]}\end{array}$ & $\begin{array}{c}11, \\
12.8(3.3)\end{array}$ & $\mathrm{CP}$ & No & $\begin{array}{c}1 \\
3 \text { days/week }\end{array}$ & 1 & 70 & $\begin{array}{c}\text { BBT } \\
\text { MAAULF }\end{array}$ & Kinematics & $\begin{array}{l}\text { - Improvement of the BBT } \\
\text { - Evidence of retention } \\
\text { - No improvements of kinematics } \\
\text { and MAAULF }\end{array}$ \\
\hline $\begin{array}{l}\text { NJIT-RAVR } \\
\text { [68] }\end{array}$ & $\begin{array}{c}4, \\
10.5(3.3)\end{array}$ & $\mathrm{CP}$ & $\begin{array}{c}4 \\
\mathrm{CP} \\
8.5(3.1)\end{array}$ & $\begin{array}{c}3 \\
3 \text { days/week }\end{array}$ & 1 & 60 & MAAULF & $\begin{array}{l}\text { Kinematics } \\
\text { Smoothness }\end{array}$ & $\begin{array}{l}\text { - Both groups improved kinematics and } \\
\text { MAUULF } \\
\text { - Feasibility of combining robotic therapy } \\
\text { with that conventional without adverse effects }\end{array}$ \\
\hline $\begin{array}{l}\text { NJIT-RAVR } \\
\text { [67] }\end{array}$ & $\begin{array}{c}2, \\
8.5(1.5)\end{array}$ & $\mathrm{CP}$ & No & $\begin{array}{c}3 \\
3 \text { days/week }\end{array}$ & 1 & 60 & MAAULF & $\begin{array}{l}\text { Kinematics } \\
\text { RoM } \\
\text { Forces }\end{array}$ & $\begin{array}{l}\text { - Improvements of motor performance } \\
\text { and kinematics }\end{array}$ \\
\hline $\begin{array}{c}\text { NJIT-RAVR } \\
\text { [69] }\end{array}$ & $\begin{array}{c}9, \\
9.4(3.5)\end{array}$ & $\mathrm{CP}$ & No & $\begin{array}{c}3 \\
3 \text { days/week }\end{array}$ & 1 & 60 & MAAULF & $\begin{array}{l}\text { Kinematics } \\
\text { RoM }\end{array}$ & $\begin{array}{l}\text { - Better active supination RoM } \\
\text { - Greater arm elevation }\end{array}$ \\
\hline $\begin{array}{l}\text { WristBot } \\
{[90]}\end{array}$ & $\begin{array}{c}1, \\
14.0(0.0)\end{array}$ & ABI & No & $\begin{array}{c}1 \\
3 \text { days/week }\end{array}$ & 1 & 60 & 1 & $\begin{array}{l}\text { Kinematics } \\
\text { Smoothenss } \\
\text { RoM }\end{array}$ & $\begin{array}{l}\text { - Improvement of smoothness } \\
\text { - Better accuracy and better control of } \\
\text { the affected limb }\end{array}$ \\
\hline $\begin{array}{l}\text { WristBot } \\
\text { [70] }\end{array}$ & $\begin{array}{c}2, \\
8.0(1.0)\end{array}$ & $\begin{array}{c}\mathrm{ABI} \\
5.0(1.0)\end{array}$ & No & $\begin{array}{c}6 \\
2 \text { days/week }\end{array}$ & 1 & 30 & $\begin{array}{l}\text { QUEST } \\
\text { MAS } \\
\text { BBT }\end{array}$ & $\begin{array}{l}\text { Kinematics } \\
\text { Smoothenss } \\
\text { RoM }\end{array}$ & $\begin{array}{l}\text { - Improvement of rad } \backslash \text { uln RoM } \\
\text { - Better accuracy } \\
\text { - Significant reduction in the amount } \\
\text { of assistive force }\end{array}$ \\
\hline $\begin{array}{l}\text { WristBot } \\
{[71]}\end{array}$ & $\begin{array}{c}1, \\
14.0(0.0)\end{array}$ & $\begin{array}{l}\text { Stroke } \\
13.0(0.0)\end{array}$ & No & $\begin{array}{c}12 \\
2 \text { days/week }\end{array}$ & 1 & 60 & $\begin{array}{l}\text { MAAULF } \\
\text { MAS } \\
\text { AHA }\end{array}$ & $\begin{array}{l}\text { Kinematics } \\
\text { Smoothenss } \\
\text { RoM }\end{array}$ & $\begin{array}{l}\text { - Higher smoothness } \\
\text { - Significant reduction in robot intervention } \\
\text { - Improvement of both distal and proximal } \\
\text { segments of upper limbs }\end{array}$ \\
\hline $\begin{array}{l}\text { Novint } \\
\text { Falcon } \\
{[28]}\end{array}$ & $\begin{array}{c}2, \\
8.5(1.5)\end{array}$ & $\mathrm{CP}$ & No & $\begin{array}{c}1 \\
3 \text { days/week }\end{array}$ & 1 & 120 & 1 & Kinematics & $\begin{array}{l}\text { - Improvement of kinematics } \\
\text { - No pain during the training }\end{array}$ \\
\hline $\begin{array}{l}\text { Amadeo } \\
{[92]}\end{array}$ & $\begin{array}{c}12 \\
9.0(3.6)\end{array}$ & ABI & No & $\begin{array}{c}6 \\
3 \text { days/week }\end{array}$ & 1 & 60 & $\begin{array}{l}\text { QUEST } \\
\text { FMA } \\
\text { AHA }\end{array}$ & $\begin{array}{l}\text { Grip forces } \\
\text { Kinematics }\end{array}$ & $\begin{array}{l}\text { - Improvements of clinical scales } \\
\text { - Improvement focused on the distal part } \\
\text { of upper limbs }\end{array}$ \\
\hline $\begin{array}{l}\text { ReHaptic } \\
\text { Handle } \\
\text { [93] }\end{array}$ & $\begin{array}{c}1, \\
8.0(0.0)\end{array}$ & $\mathrm{CP}$ & No & $\begin{array}{c}2 \\
3 \text { days/week }\end{array}$ & 1 & 60 & 1 & $\begin{array}{l}\text { Kinematics } \\
\text { Smoothness }\end{array}$ & $\begin{array}{l}\text { - Improvement of kinematics and } \\
\text { smoothness }\end{array}$ \\
\hline $\begin{array}{l}\text { REAPlan } \\
\text { [15] }\end{array}$ & $\begin{array}{c}8, \\
10.8(4.6)\end{array}$ & $\mathrm{CP}$ & $\begin{array}{c}8 \\
\mathrm{CP} \\
11.0(3.5)\end{array}$ & $\begin{array}{c}8 \\
5 \text { days/week }\end{array}$ & 1 & 45 & $\begin{array}{l}\text { QUEST } \\
\text { MAS } \\
\text { BBT }\end{array}$ & $\begin{array}{l}\text { Kinematics } \\
\text { Forces } \\
\text { Spasticity }\end{array}$ & $\begin{array}{l}\text { - Kinematics and manual dexterity improved } \\
\text { more in the group undergoing robotic therapy }\end{array}$ \\
\hline
\end{tabular}




\section{Discussion}

The first consideration that can be drawn from this review on the current state of the clinical application of robot technologies in the rehabilitation of children affected by neuromotor impairments, is that it is in a very preliminary stage of development. The absence of any Cochrane review on this topic is a clear sign of this situation, in contrast with the fact that several reviews have been edited in recent years on the use of the same technologies for adult patients $[95,96]$.

One reason is that in the great majority of cases, the mechatronic design of the robotic systems was tailored on adult subjects and the possibility of adapting the systems to children, in different stages of physical and neural development, was quite limited. Moreover, considering that stroke was and is the clinical condition for which most robotic systems were designed, the emphasis was on motor impairment (hemiparesis or hemiplegia) with the development of control algorithms intended to promote neuroplasticity and motor learning during rehabilitation after neurological injury. The consideration of non-motor aspects of the pathological condition was rather limited and focused on the involvement of the user's attention and motivation by means of "entertainment" techniques typical of video games. However, in the case of children, the motor impairment is always strongly associated with perceptual and cognitive impairments and all of them (motor-perceptual-cognitive) constrain and condition the neurodevelopment process. Thus the robot-child interaction cannot be limited to the purely motor aspect but must be integrated in a ludic/playful environment, or educational in a large sense, that mixes physical intervention with sensorimotor assessment and adaptation to the stages of child development.

Another interesting aspect relates to the sensorimotor assessment, that is even more critical with children than with adults in the earliest phase of pathological conditions. If for adult subjects the cerebro-vascular accidents are easily detected, with low diagnostic uncertainty, in perinatal stroke it is more difficult to identify, and such difficulty may entail eventual delays in clinical decision about rehabilitation that could compromise neural plasticity and therefore functional recovery. This is why appropriate assessment methods have a pivotal importance and should be an integral part of the repository of technologies to be used for supporting neuromotor rehabilitation. As an example, the observation of spontaneous movements in newborn babies, particularly in the case of prematurity, could be a reliable indicator of emerging neuromotor impairments and thus can be used as a method of early prediction of cerebral palsy [97], motivating the development of various techniques of computer-based video analysis, e.g., [98], that carry out at the same time an assessment and early diagnostic function. The logical consequence is to link early intervention to early diagnosis, as supported by a recent Cochrane review [99] that emphasizes the relevant influence of early intervention on the neurodevelopmental process, provided that such interaction is associated with active (e.g., child-initiated) task-related actions with social and environmental engagement. As a second important result emerged from the reviewed studies, is the identification of intensity, task-specificity and amount of practice as key aspects that make functional recovery successful. However, applying this scenario in clinical rehabilitation would result in a high number of physical resources involved, and therefore high costs, to deliver the high dose of training necessary to promote neuroplasticity and motor recover. Therefore, the use of robotic therapy could be the optimal solution, to reduce the health system costs and, at the same time, to ensure a high-level therapy. In this review it also emerged that robotic devices could represent a more objective and reliable measurement tool to assess children's motor functions. We aimed at providing a comprehensive overview of how the combination of robotic evaluations with clinical scales has been demonstrate to be a defined image of motor performance, allowing clinicians to design a more personalized therapeutic protocol. Besides, the definition of the most suitable protocol cannot be done regardless of the specific neurological disorder and its resulting motor and/or sensory impairments and some of the examined studies also pointed out the need to include protocols for the unimpaired arm which, in most cases, presents abnormal responses. 
Finally, in the present review study we put particular emphasis on the control strategies implemented on the different devices and the assistive mode emerged to be the one most commonly adopted. Training protocols based on such assistance were well tolerated and promoted recovery of children's damaged sensorimotor skills. However, the discussion about which is the most effective control strategy among the assistive modalities and the most reliable assessment approach is still open. To solve this problem, further studies are needed to obtain a common understanding leading to the design of effective training protocols and to identify the most robust control strategy. Based on the above results and on the limits detected in the examined clinical protocols, future perspectives on the design of clinical protocols should include: homogeneous group of patients, a control group of patients with the same disease that does not undergo robotic intervention, test of the maintenance of acquired gains and, when possible, the evaluation of treatment effects on brain activity through neurophysiology and neuroimaging techniques.

Author Contributions: Conceptualization, J.Z. and F.M.; methodology, V.F.; investigation, V.F.; writing—original draft preparation, V.F.; writing-review and editing, J.Z., F.M. and P.M.

Funding: This research received no external funding.

Conflicts of Interest: The authors declare no conflict of interest.

\section{References}

1. Cook, A.; Encarnação, P.; Adams, K. Robots: Assistive technologies for play, learning and cognitive development. Technol. Disabil. 2010, 22, 127-145. [CrossRef]

2. Odding, E.; Roebroeck, M.E.; Stam, H.J. The epidemiology of cerebral palsy: Incidence, impairments and risk factors. Disabil. Rehabil. 2006, 28, 183-191. [CrossRef] [PubMed]

3. Eunson, P. Aetiology and epidemiology of cerebral palsy. Paediatr. Child Health 2012, 22, 361-366. [CrossRef]

4. Morris, C. Definition and classification of cerebral palsy: A historical perspective. Dev. Med. Child Neurol. 2007, 49, 3-7. [CrossRef]

5. Raju, T.N.; Nelson, K.B.; Ferriero, D.; Lynch, J.K. Ischemic perinatal stroke: Summary of a workshop sponsored by the National Institute of Child Health and Human Development and the National Institute of Neurological Disorders and Stroke. Pediatrics 2007, 120, 609-616. [CrossRef] [PubMed]

6. Mallick, A.A.; O'Callaghan, F.J. The epidemiology of childhood stroke. Eur. J. Paediatr. Neurol. 2010, 14, 197-205. [CrossRef] [PubMed]

7. Eeg-Olofsson, O.; Ringheim, Y. Stroke in children. Clinical characteristics and prognosis. Acta Paediatr. 1983, 72, 391-395. [CrossRef]

8. Morrissey, K.; Fairbrother, H. Severe Traumatic Brain Injury In Children: An Evidence-Based Review of Emergency Department Management. Pediatr. Emerg. Med. Pract. 2016, 13, 1-28. [PubMed]

9. Thurman, D.J. The Epidemiology of Traumatic Brain Injury in Children and Youths: A Review of Research Since 1990. J. Child Neurol. 2016, 31, 20-27. [CrossRef]

10. Jones, M.W.; Morgan, E.; Shelton, J.E.; Thorogood, C. Cerebral palsy: Introduction and diagnosis (part I). J. Pediatr. Health Care 2007, 21, 146-152. [CrossRef]

11. Steenbergen, B.; Veringa, A.; de Haan, A.; Hulstijn, W. Manual dexterity and keyboard use in spastic hemiparesis: A comparison between the impaired hand and the 'good' hand on a number of performance measures. Clin. Rehabil. 1998, 12, 64-72. [CrossRef] [PubMed]

12. Maciejasz, P.; Eschweiler, J.; Gerlach-Hahn, K.; Jansen-Troy, A.; Leonhardt, S. A survey on robotic devices for upper limb rehabilitation. J. Neuroeng. Rehabil. 2014, 11, 3. [CrossRef] [PubMed]

13. Meyer-Heim, A.; van Hedel, H.J. Robot-assisted and computer-enhanced therapies for children with cerebral palsy: Current state and clinical implementation. In Seminars in Pediatric Neurology; Elsevier: Amsterdam, The Netherlands, 2013; Volume 20, pp. 139-145.

14. Fasoli, S.E.; Fragala-Pinkham, M.; Hughes, R.; Hogan, N.; Krebs, H.I.; Stein, J. Upper limb robotic therapy for children with hemiplegia. Am. J. Phys. Med. Rehabil. 2008, 87, 929-936. [CrossRef] [PubMed]

15. Gilliaux, M.; Renders, A.; Dispa, D.; Holvoet, D.; Sapin, J.; Dehez, B.; Detrembleur, C.; Lejeune, T.M.; Stoquart, G. Upper limb robot-assisted therapy in cerebral palsy: A single-blind randomized controlled trial. Neurorehabilit. Neural Repair 2015, 29, 183-192. [CrossRef] [PubMed] 
16. Rose, F.; Johnson, D.; Attree, E. Rehabilitation of the head-injured child: Basic research and new technology. Pediatr. Rehabil. 1997, 1, 3-7. [CrossRef] [PubMed]

17. Damiano, D.L. Activity, activity, activity: Rethinking our physical therapy approach to cerebral palsy. Phys. Ther. 2006, 86, 1534-1540. [CrossRef] [PubMed]

18. Emken, J.L.; Benitez, R.; Sideris, A.; Bobrow, J.E.; Reinkensmeyer, D.J. Motor adaptation as a greedy optimization of error and effort. J. Neurophysiol. 2007, 97, 3997-4006. [CrossRef] [PubMed]

19. Su, Y.S.; Veeravagu, A.; Grant, G. Neuroplasticity after traumatic brain injury. In Translational Research in Traumatic Brain Injury; Laskowitz, D., Grant, G., Eds.; CRC Press/Taylor and Francis Group: Boca Raton, FL, USA, 2016.

20. Vahdat, S.; Darainy, M.; Thiel, A.; Ostry, D.J. A Single Session of Robot-Controlled Proprioceptive Training Modulates Functional Connectivity of Sensory Motor Networks and Improves Reaching Accuracy in Chronic Stroke. Neurorehabilit. Neural Repair 2019, 33, 70-81. [CrossRef] [PubMed]

21. Ladenheim, B.; Altenburger, P.; Cardinal, R.; Monterroso, L.; Dierks, T.; Mast, J.; Krebs, H.I. The effect of random or sequential presentation of targets during robot-assisted therapy on children. NeuroRehabilitation 2013, 33, 25-31.

22. Reid, L.B.; Rose, S.E.; Boyd, R.N. Rehabilitation and neuroplasticity in children with unilateral cerebral palsy. Nat. Rev. Neurol. 2015, 11, 390. [CrossRef]

23. Reid, L.B.; Pagnozzi, A.M.; Fiori, S.; Boyd, R.N.; Dowson, N.; Rose, S.E. Measuring neuroplasticity associated with cerebral palsy rehabilitation: An MRI based power analysis. Int. J. Dev. Neurosci. 2017, 58, 17-25. [CrossRef] [PubMed]

24. Krebs, H.I.; Fasoli, S.E.; Dipietro, L.; Fragala-Pinkham, M.; Hughes, R.; Stein, J.; Hogan, N. Motor learning characterizes habilitation of children with hemiplegic cerebral palsy. Neurorehabilit. Neural Repair 2012, 26, 855-860. [CrossRef] [PubMed]

25. Ríos-Rincón, A.M.; Adams, K.; Magill-Evans, J.; Cook, A. Playfulness in children with limited motor abilities when using a robot. Phys. Occup. Ther. Pediatr. 2016, 36, 232-246. [CrossRef] [PubMed]

26. Frascarelli, F.; Masia, L.; Di, G.R.; Cappa, P.; Petrarca, M.; Castelli, E.; Krebs, H. The impact of robotic rehabilitation in children with acquired or congenital movement disorders. Eur. J. Phys. Rehabil. Med. 2009, 45, 135-141. [PubMed]

27. Ouellette, M.M.; LeBrasseur, N.K.; Bean, J.F.; Phillips, E.; Stein, J.; Frontera, W.R.; Fielding, R.A. High-intensity resistance training improves muscle strength, self-reported function, and disability in long-term stroke survivors. Stroke 2004, 35, 1404-1409. [CrossRef] [PubMed]

28. Elsaeh, M.; Pudlo, P.; Djemai, M.; Bouri, M.; Thevenon, A.; Heymann, I. The effects of haptic-virtual reality game therapy on brain-motor coordination for children with hemiplegia: A pilot study. In Proceedings of the IEEE 2017 International Conference on Virtual Rehabilitation (ICVR), Montreal, QC, Canada, 19-22 June 2017; pp. 1-6.

29. Marchal-Crespo, L.; Reinkensmeyer, D.J. Review of control strategies for robotic movement training after neurologic injury. J. Neuroeng. Rehabil. 2009, 6, 20. [CrossRef] [PubMed]

30. Bayon, C.; Raya, R.; Lara, S.; Ramírez, O.; Serrano, J.; Rocon, E. Robotic therapies for children with cerebral palsy: A systematic review. Transl. Biomed. 2016, 7, 44. [CrossRef]

31. Berdina, O.N.; Bairova, T.A.; Rychkova, L.V.; Sheptunov, S.A. The pediatric robotic-assisted rehabilitation complex for children and adolescents with cerebral palsy: Background and product design. In Proceedings of the IEEE 2017 International Conference on “Quality Management, Transport and Information Security, Information Technologies” (IT\&QM\&IS), St. Petersburg, Russia, 24-30 September 2017; pp. 360-363.

32. Gilliaux, M.; Dierckx, F.; Berghe, L.V.; Lejeune, T.M.; Sapin, J.; Dehez, B.; Stoquart, G.; Detrembleur, C. Age effects on upper limb kinematics assessed by the REAplan robot in healthy school-aged children. Ann. Biomed. Eng. 2015, 43, 1123-1131. [CrossRef]

33. Laut, J.; Porfiri, M.; Raghavan, P. The present and future of robotic technology in rehabilitation. Curr. Phys. Med. Rehabil. Rep. 2016, 4, 312-319. [CrossRef]

34. DeMatteo, C.; Law, M.; Russell, D.; Pollock, N.; Rosenbaum, P.; Walter, S. The reliability and validity of the Quality of Upper Extremity Skills Test. Phys. Occup. Ther. Pediatr. 1993, 13, 1-18. [CrossRef]

35. Charalambous, C.P. Interrater reliability of a modified Ashworth scale of muscle spasticity. In Classic Papers in Orthopaedics; Springer: Berlin, Germany, 2014; pp. 415-417. 
36. de Bode, S.; Firestine, A.; Mathern, G.W.; Dobkin, B. Residual motor control and cortical representations of function following hemispherectomy: Effects of etiology. J. Child Neurol. 2005, 20, 64-75. [CrossRef] [PubMed]

37. Johnson, L.M.; Randall, M.J.; Reddihough, D.S.; Byrt, T.; Oke, L.; Bach, T. Development of a clinical assessment of quality of movement for unilateral upper-limb function. Dev. Med. Child Neurol. 1994, 36, 965-973. [CrossRef] [PubMed]

38. Rosa-Rizzotto, M.; Visona Dalla Pozza, L.; Corlatti, A.; Luparia, A.; Marchi, A.; Molteni, F.; Fedrizzi, E.; Group, G.S.; et al. A new scale for the assessment of performance and capacity of hand function in children with hemiplegic cerebral palsy: Reliability and validity studies. Eur. J. Phys. Rehabil. Med. 2014, 50, 543-556. [PubMed]

39. Krumlinde-Sundholm, L.; Holmefur, M.; Kottorp, A.; Eliasson, A.C. The Assisting Hand Assessment: Current evidence of validity, reliability, and responsiveness to change. Dev. Med. Child Neurol. 2007, 49, 259-264. [CrossRef] [PubMed]

40. Mathiowetz, V.; Volland, G.; Kashman, N.; Weber, K. Adult norms for the Box and Block Test of manual dexterity. Am. J. Occup. Ther. 1985, 39, 386-391. [CrossRef] [PubMed]

41. Fasoli, S.E.; Fragala-Pinkham, M.; Hughes, R.; Hogan, N.; Stein, J.; Krebs, H.I. Upper limb robot-assisted therapy: A new option for children with hemiplegia. Technol. Disabil. 2010, 22, 193-198. [CrossRef]

42. Chen, Y.P.; Howard, A.M. Effects of robotic therapy on upper-extremity function in children with cerebral palsy: A systematic review. Dev. Neurorehabilit. 2016, 19, 64-71. [CrossRef]

43. Fasoli, S.E.; Ladenheim, B.; Mast, J.; Krebs, H.I. New horizons for robot-assisted therapy in pediatrics. Am. J. Phys. Med. Rehabil. 2012, 91, S280-S289. [CrossRef] [PubMed]

44. Sanchez, R.; Reinkensmeyer, D.; Shah, P.; Liu, J.; Rao, S.; Smith, R.; Cramer, S.; Rahman, T.; Bobrow, J. Monitoring functional arm movement for home-based therapy after stroke. In Proceedings of the IEEE 26th Annual International Conference of the IEEE Engineering in Medicine and Biology Society, San Francisco, CA, USA, 1-5 September 2004; Volume 2, pp. 4787-4790.

45. Krebs, H.I.; Hogan, N.; Aisen, M.L.; Volpe, B.T. Robot-aided neurorehabilitation. IEEE Trans. Rehabil. Eng. 1998, 6, 75-87. [CrossRef] [PubMed]

46. Scott, S.H. Apparatus for measuring and perturbing shoulder and elbow joint positions and torques during reaching. J. Neurosci. Methods 1999, 89, 119-127. [CrossRef]

47. Sukal, T.M.; Ellis, M.D.; Dewald, J.P. Shoulder abduction-induced reductions in reaching work area following hemiparetic stroke: Neuroscientific implications. Exp. Brain Res. 2007, 183, 215-223. [CrossRef] [PubMed]

48. Adamovich, S.V.; Fluet, G.G.; Merians, A.S.; Mathai, A.; Qiu, Q. Incorporating haptic effects into three-dimensional virtual environments to train the hemiparetic upper extremity. IEEE Trans. Neural Syst. Rehabil. Eng. 2009, 17, 512-520. [CrossRef] [PubMed]

49. Zhu, T.L.; Klein, J.; Dual, S.A.; Leong, T.C.; Burdet, E. reachMAN2: A compact rehabilitation robot to train reaching and manipulation. In Proceedings of the 2014 IEEE/RSJ International Conference on Intelligent Robots and Systems, Chicago, IL, USA, 14-18 September 2014; pp. 2107-2113.

50. Gallagher, J.; Preston, N.; Holt, R.; Mon-Williams, M.; Levesley, M.; Weightman, A. Assessment of upper limb movement with an autonomous robotic device in a school environment for children with Cerebral Palsy. In Proceedings of the 2015 IEEE International Conference on Rehabilitation Robotics (ICORR), Singapore, Singapore, 11-14 August 2015; pp. 770-774.

51. Keller, U.; Klamroth, V.; van Hedel, H.J.; Riener, R. ChARMin: A robot for pediatric arm rehabilitation. In Proceedings of the 2013 IEEE International Conference on Robotics and Automation, Karlsruhe, Germany, 6-10 May 2013; pp. 3908-3913.

52. Keller, U.; Rauter, G.; Riener, R. Assist-as-needed path control for the PASCAL rehabilitation robot. In Proceedings of the 2013 IEEE 13th International Conference on Rehabilitation Robotics (ICORR), Seattle, WA, USA, 24-26 June 2013; pp. 1-7.

53. Stein, J.; Bishop, L.; Gillen, G.; Helbok, R. Robot-assisted exercise for hand weakness after stroke: A pilot study. Am. J. Phys. Med. Rehabil. 2011, 90, 887-894. [CrossRef] [PubMed]

54. Masia, L.; Casadio, M.; Giannoni, P.; Sandini, G.; Morasso, P. Performance adaptive training control strategy for recovering wrist movements in stroke patients: A preliminary, feasibility study. J. Neuroeng. Rehabil. 2009, 6, 44. [CrossRef] [PubMed] 
55. Aubin, P.M.; Sallum, H.; Walsh, C.; Stirling, L.; Correia, A. A pediatric robotic thumb exoskeleton for at-home rehabilitation: The Isolated Orthosis for Thumb Actuation (IOTA). In Proceedings of the 2013 IEEE 13th International Conference on Rehabilitation Robotics (ICORR), Seattle, WA, USA, 24-26 June 2013; pp. 1-6.

56. Martin, S.; Hillier, N. Characterisation of the Novint Falcon haptic device for application as a robot manipulator. In Proceedings of the Australasian Conference on Robotics and Automation (ACRA), Sydney, Australia, 2-4 December 2009; pp. 291-292.

57. Hogan, N.; Krebs, H.I.; Charnnarong, J.; Srikrishna, P.; Sharon, A. MIT-MANUS: A workstation for manual therapy and training. I. In Proceedings of the IEEE International Workshop on Robot and Human Communication, Tokyo, Japan, 1992; pp. 161-165.

58. Van der Linde, R.Q.; Lammertse, P.; Frederiksen, E.; Ruiter, B. The HapticMaster, a new high-performance haptic interface. In Proceedings of the Eurohaptics, Edinburgh, UK, 8-10 July 2002; pp. 1-5.

59. Riener, R.; Lünenburger, L.; Maier, I.C.; Colombo, G.; Dietz, V. Locomotor training in subjects with sensori-motor deficits: An overview of the robotic gait orthosis lokomat. J. Healthc. Eng. 2010, 1, 197-216. [CrossRef]

60. Koenig, A.; Keller, U.; Pfluger, K.; Meyer-Heim, A.; Riener, R. PASCAL: Pediatric arm support robot for combined arm and leg training. In Proceedings of the 2012 4th IEEE RAS \& EMBS International Conference on Biomedical Robotics and Biomechatronics (BioRob), Rome, Italy, 24-27 June 2012; pp. 1862-1868.

61. Keller, U.; Riener, R. Design of the pediatric arm rehabilitation robot ChARMin. In Proceedings of the 5th IEEE RAS/EMBS International Conference on Biomedical Robotics and Biomechatronics, Sao Paulo, Brazil, 12-15 August 2014; pp. 530-535.

62. Aggogeri, F.; Mikolajczyk, T.; O'Kane, J. Robotics for rehabilitation of hand movement in stroke survivors. Adv. Mech. Eng. 2019, 11, 1-14. [CrossRef]

63. Keller, U.; van Hedel, H.J.; Klamroth-Marganska, V.; Riener, R. ChARMin: The first actuated exoskeleton robot for pediatric arm rehabilitation. IEEE/ASME Trans. Mechatron. 2016, 21, 2201-2213. [CrossRef]

64. Frascarelli, F.; Masia, L.; Di Rosa, G.; Petrarca, M.; Cappa, P.; Castelli, E. Robot-mediated and clinical scales evaluation after upper limb botulinum toxin type a injection in children with hemiplegia. J. Rehabil. Med. 2009, 41, 988-994. [CrossRef]

65. Bosecker, C.; Dipietro, L.; Volpe, B.; Igo Krebs, H. Kinematic robot-based evaluation scales and clinical counterparts to measure upper limb motor performance in patients with chronic stroke. Neurorehabilit. Neural Repair 2010, 24, 62-69. [CrossRef]

66. Dukelow, S.P.; Herter, T.M.; Moore, K.D.; Demers, M.J.; Glasgow, J.I.; Bagg, S.D.; Norman, K.E.; Scott, S.H. Quantitative assessment of limb position sense following stroke. Neurorehabilit. Neural Repair 2010, 24, 178-187. [CrossRef]

67. Qiu, Q.; Ramirez, D.A.; Saleh, S.; Fluet, G.G.; Parikh, H.D.; Kelly, D.; Adamovich, S.V. The New Jersey Institute of Technology Robot-Assisted Virtual Rehabilitation (NJIT-RAVR) system for children with cerebral palsy: A feasibility study. J. Neuroeng. Rehabil. 2009, 6, 40. [CrossRef] [PubMed]

68. Fluet, G.G.; Qiu, Q.; Saleh, S.; Ramirez, D.; Adamovich, S.; Kelly, D.; Parikh, H. Robot-assisted virtual rehabilitation (NJIT-RAVR) system for children with upper extremity hemiplegia. In Proceedings of the 2009 Virtual Rehabilitation International Conference, Haifa, Israel, 29 June-2 July 2009; pp. 189-192.

69. Fluet, G.G.; Qiu, Q.; Kelly, D.; Parikh, H.D.; Ramirez, D.; Saleh, S.; Adamovich, S.V. Interfacing a haptic robotic system with complex virtual environments to treat impaired upper extremity motor function in children with cerebral palsy. Dev. Neurorehabilit. 2010, 13, 335-345. [CrossRef] [PubMed]

70. Marini, F.; Squeri, V.; Cappello, L.; Morasso, P.; Riva, A.; Doglio, L.; Masia, L. Adaptive wrist robot training in pediatric rehabilitation. In Proceedings of the 2015 IEEE International Conference on Rehabilitation Robotics (ICORR), Singapore, Singapore, 11-14 August 2015; pp. 175-180.

71. Marini, F.; Hughes, C.M.; Squeri, V.; Doglio, L.; Moretti, P.; Morasso, P.; Masia, L. Robotic wrist training after stroke: Adaptive modulation of assistance in pediatric rehabilitation. Robot. Auton. Syst. 2017, 91, 169-178. [CrossRef]

72. Taylor, J. Proprioception. In Encyclopedia of Neuroscience; Squire, L.R., Ed.; Academic Press: Oxford, UK, 2009; pp. 1143-1149.

73. Kuczynski, A.M.; Semrau, J.A.; Kirton, A.; Dukelow, S.P. Kinesthetic deficits after perinatal stroke: Robotic measurement in hemiparetic children. J. Neuroeng. Rehabil. 2017, 14, 13. [CrossRef] [PubMed] 
74. Kuczynski, A.M.; Kirton, A.; Semrau, J.A.; Dukelow, S.P. Bilateral reaching deficits after unilateral perinatal ischemic stroke: A population-based case-control study. J. Neuroeng. Rehabil. 2018, 15, 77. [CrossRef] [PubMed]

75. Krebs, H.I.; Palazzolo, J.J.; Dipietro, L.; Ferraro, M.; Krol, J.; Rannekleiv, K.; Volpe, B.T.; Hogan, N. Rehabilitation robotics: Performance-based progressive robot-assisted therapy. Auton. Robot. 2003, 15, 7-20. [CrossRef]

76. Masia, L.; Frascarelli, F.; Morasso, P.; Di Rosa, G.; Petrarca, M.; Castelli, E.; Cappa, P. Abnormal adaptation in children affected by cerebral palsy to robot generated dynamic environment. In Proceedings of the 2010 Annual International Conference of the IEEE Engineering in Medicine and Biology, Buenos Aires, Argentina, 31 August-4 September 2010; pp. 3410-3413.

77. Masia, L.; Frascarelli, F.; Morasso, P.; Di Rosa, G.; Petrarca, M.; Castelli, E.; Cappa, P. Reduced short term adaptation to robot generated dynamic environment in children affected by Cerebral Palsy. J. Neuroeng. Rehabil. 2011, 8, 28. [CrossRef] [PubMed]

78. Fasoli, S.E.; Fragala-Pinkham, M.; Hughes, R.; Krebs, H.I.; Hogan, N.; Stein, J. Robotic therapy and botulinum toxin type A: A novel intervention approach for cerebral palsy. Am. J. Phys. Med. Rehabil. 2008, 87, 1022-1026. [CrossRef]

79. Turner, D.L.; Winterbotham, W.; Kmetova, M. Using assistive robotic technology in motor neurorehabilitation after childhood stroke. J. Neurol. Res. 2012, 2, 65-68. [CrossRef]

80. Aharonson, V.; Krebs, H.I. Prediction of response to robot-aided motor neuro-rehabilitation of children with cerebral palsy. Biomed. Signal Process. Control 2012, 7, 180-184. [CrossRef]

81. Cimolin, V.; Vagnini, A.; Germiniasi, C.; Galli, M.; Pacifici, I.; Negri, L.; Beretta, E.; Piccinini, L. The Armeo spring as training tool to improve upper limb functionality in hemiplegic cerebral palsy: A pilot study. In Proceedings of the 2016 IEEE 2nd International Forum on Research and Technologies for Society and Industry Leveraging a better tomorrow (RTSI), Bologna, Italy, 7-9 September 2016; pp. 1-4.

82. Biffi, E.; Maghini, C.; Cairo, B.; Beretta, E.; Peri, E.; Altomonte, D.; Mazzoli, D.; Giacobbi, M.; Prati, P.; Merlo, A.; et al. Movement Velocity and Fluidity Improve after Armeo ${ }^{\circledR}$ Spring Rehabilitation in Children Affected by Acquired and Congenital Brain Diseases: An Observational Study. BioMed Res. Int. 2018, 2018, 1537170. [CrossRef] [PubMed]

83. Cimolin, V.; Germiniasi, C.; Galli, M.; Condoluci, C.; Beretta, E.; Piccinini, L. Robot-Assisted Upper Limb Training for Hemiplegic Children with Cerebral Palsy. J. Dev. Phys. Disabil. 2019, 31, 89-101. [CrossRef]

84. Turconi, A.C.; Biffi, E.; Maghini, C.; Peri, E.; Servodio, F.I.; Gagliardi, C. Can new technologies improve upper limb performance in grown-up diplegic children? Eur. J. Phys. Rehabil. Med. 2016, 52, 672-681. [PubMed]

85. El-Shamy, S.M. Efficacy of Armeo ${ }^{\circledR}$ robotic therapy versus conventional therapy on upper limb function in children with hemiplegic cerebral palsy. Am. J. Phys. Med. Rehabil. 2018, 97, 164-169. [CrossRef] [PubMed]

86. Beretta, E.; Cesareo, A.; Biffi, E.; Schafer, C.; Galbiati, S.; Strazzer, S. Rehabilitation of Upper Limb in Children with Acquired Brain Injury: A Preliminary Comparative Study. J. Healthc. Eng. 2018, 3, 1-12. [CrossRef] [PubMed]

87. Peri, E.; Biffi, E.; Maghini, C.; Iammarrone, F.S.; Gagliardi, C.; Germiniasi, C.; Pedrocchi, A.; Turconi, A.C.; Reni, G. Quantitative evaluation of performance during robot-assisted treatment. Methods Inf. Med. 2016, 55, 84-88. [PubMed]

88. Sukal, T.M.; Krosschell, K.J.; Dewald, J.P. Use of the ACT3D system to evaluate synergies in children with spastic hemiparetic cerebral palsy: A pilot study. In Proceedings of the 2007 IEEE 10th International Conference on Rehabilitation Robotics, Noordwijk, The Netherlands, 13-15 June 2007; pp. 964-967.

89. Sukal, T.M.; Ellis, M.D.; Dewald, J.P. Dynamic characterization of upper limb discoordination following hemiparetic stroke. In Proceedings of the 9th International Conference on Rehabilitation Robotics, Chicago, IL, USA, 28 June-1 July 2005; pp. 519-521.

90. Marini, F.; Cappello, L.; Squeri, V.; Morasso, P.; Moretti, P.; Riva, A.; Doglio, L.; Masia, L. Online modulation of assistance in robot aided wrist rehabilitation a pilot study on a subject affected by dystonia. In Proceedings of the 2014 IEEE Haptics Symposium (HAPTICS), Houston, TX, USA, 23-26 February 2014; pp. 153-158.

91. Jakob, I.; Kollreider, A.; Germanotta, M.; Benetti, F.; Cruciani, A.; Padua, L.; Aprile, I. Robotic and sensor technology for upper limb rehabilitation. PMER 2018, 10, S189-S197. 
92. Bishop, L.; Gordon, A.M.; Kim, H. Hand Robotic Therapy in Children with Hemiparesis: A Pilot Study. Am. J. Phys. Med. Rehabil. 2017, 96, 1-7. [CrossRef] [PubMed]

93. Tong, L.Z.; Ong, H.T.; Tan, J.X.; Lin, J.; Burdet, E.; Ge, S.; Teo, C.L. Pediatric rehabilitation with the reachMAN's modular handle. In Proceedings of the 2015 37th Annual International Conference of the IEEE Engineering in Medicine and Biology Society (EMBC), Milano, Italy, 25-29 August 2015; pp. 3933-3936.

94. Keller, J.W.; Van Hedel, H.J. Weight-supported training of the upper extremity in children with cerebral palsy: A motor learning study. J. Neuroeng. Rehabil. 2017, 14, 87. [CrossRef]

95. Mehrholz, J.; Hädrich, A.; Platz, T.; Kugler, J.; Pohl, M. Electromechanical and robot-assisted arm training for improving generic activities of daily living, arm function, and arm muscle strength after stroke. Cochrane Database Syst. Rev. 2012, 6, CD006876. [CrossRef]

96. Mehrholz, J.; Thomas, S.; Werner, C.; Kugler, J.; Pohl, M.; Elsner, B. Electromechanical-assisted training for walking after stroke. Cochrane Database Syst. Rev. 2017, 5, CD006185. [CrossRef] [PubMed]

97. Prechtl, H.F. General movement assessment as a method of developmental neurology: New paradigms and their consequences The 1999 Ronnie MacKeith Lecture. Dev. Med. Child Neurol. 2001, 43, 836-842. [CrossRef] [PubMed]

98. Adde, L.; Helbostad, J.L.; Jensenius, A.R.; Taraldsen, G.; Grunewaldt, K.H.; Støen, R. Early prediction of cerebral palsy by computer-based video analysis of general movements: A feasibility study. Dev. Med. Child Neurol. 2010, 52, 773-778. [CrossRef] [PubMed]

99. Spittle, A.; Orton, J.; Anderson, P.; Boyd, R.; Doyle, L.W. Early developmental intervention programmes post-hospital discharge to prevent motor and cognitive impairments in preterm infants. Cochrane Database Syst. Rev. 2012, 12, CD005495. [CrossRef] [PubMed]

(C) 2019 by the authors. Licensee MDPI, Basel, Switzerland. This article is an open access article distributed under the terms and conditions of the Creative Commons Attribution (CC BY) license (http:/ / creativecommons.org/licenses/by/4.0/). 